\title{
CYSTIC FIBROSIS AND CAREER COUNSELLING
}

\author{
Marija Vita Zupanič ${ }^{1}$, Alenka Škerjanc ${ }^{2}$ \\ ${ }^{1}$ University Medical Centre Maribor, Department of Ophthalmology, Maribor, Slovenia \\ ${ }^{2}$ University Medical Centre Ljubljana, Clinical Institute for Occupational, Traffic and Sports Medicine, Ljubljana, Slovenia
}

\section{SUMMARY}

Objective: Cystic fibrosis is a genetic disorder that affects mostly lungs but also other organs. Modern treatment has transformed once fatal disease of childhood into the chronic disease of adulthood. Hence more patients enter the job market. Very few adolescents with cystic fibrosis receive some formal career guidance. There is still no professional career guidance for them in Slovenia.

Methods: Literature on workability of patients with cystic fibrosis was reviewed. Following the articles and Slovenian and foreign manuals the guidelines on career counselling of young patients with cystic fibrosis is proposed, as well as the suggestions for professional qualification of these patients.

Results: The results of the studies present that workability of patients with cystic fibrosis is associated to forced expiratory volume in 1 second $\left(\mathrm{FEV}_{1}\right)(p<0.05)$, the achieved educational level more than 3 years of faculty study $(p<0.001-p<0.013)$, self-assessment of quality of life $(p=0.005)$, age $(p=0.01)$, and the number of admissions to the hospital $(p=0.001)$.

Conclusions: The interactions among work, quality of life and survival require that healthcare workers strive to help their patients with cystic fibrosis to succeed in their professional lives. The young patients should achieve the highest level of education possible and follow their wishes in line with the realistic possibilities.

Key words: cystic fibrosis, workability, career counselling

Address for correspondence: A. Škerjanc, University Medical Centre Ljubljana, Clinical Institute for Occupational, Traffic and Sports Medicine, Zaloska cesta 002, 1000 Ljubljana, Slovenia. E-mail: alenka.skerjanc@gmail.com

https://doi.org/10.21101/cejph.a5634

\section{INTRODUCTION}

Cystic fibrosis (CF) is the most common lethal autosomal recessive genetic disorder that affects mostly lungs and gastrointestinal tract but also other organs. Defective ion channel results in thickened mucus in the respiratory system and other affected organs, enabling excessive growth of bacteria and fungi. This leads to numerous clinical problems: bronchiectasis with chronical bacterial infections, chronic sinusitis and nasal polyps, pancreatic insufficiency with malabsorption, cholecystolithiasis, liver involvement, distal intestinal obstruction syndrome, diabetes, osteoporosis and osteopenia, and obstructive azoospermia in men (1).

Over the last decades modern treatment has transformed this once fatal disease of childhood into the chronic disease of adulthood. Life expectancy of these patients is increasing, exceeding 40 years in some European and North American countries. In Slovenia median age of patients at death was 28 years in the last ten years (2). Increasing life expectancy of patients with CF has allowed for greater labour force participation in this population (3, 4). As patients with $\mathrm{CF}$ live longer, healthier and more independent lives, many more enter the employment market $(5,6)$. Adulthood brings many challenges to the patients therefore at the transition into adulthood the patients require specific guidance, which includes career counselling $(1,5)$. Very few adolescents with cystic fibrosis receive some formal career guidance, probably because little is known about the work life of adult CF patients $(6,7)$.

There is still no career counselling for CF patients in Slov- enia. However, the Slovenian model for transition of adolescents from paediatric to adult medical care includes some professional guidance about education, profession and occupation that the adolescents would like to pursue (8).

\section{MATERIALS AND METHODS}

The literature on workability of patients with CF was collected. On PubMed there was a review article published in 2012 on $\mathrm{CF}$ and workplace. It was exposed that only nine articles were published between 1979 and 2009 (9).

Psycho-social approach was missing in the studies. Employability and employment are affected by many factors (10). But without psycho-social risk factors being involved the influence on workability of patients with $\mathrm{CF}$ cannot be evaluated and also suggestions how to improve workability cannot be given.

Following the papers and guidance the proposal for career counselling of young patients with CF and the proposal for the professional qualification of these patients were prepared.

\section{RESULTS}

\section{Characteristics of Disease}

The target organs affected by CF, the complications of the disease and its treatment are presented in Table 1. 
Table 1. Target organs, possible complications and treatment of cystic fibrosis affecting workability

\begin{tabular}{|c|c|c|}
\hline Target organs & Complications & Treatment \\
\hline \multicolumn{3}{|c|}{ Respiratory system } \\
\hline Sinuses & Chronic infection of respiratory airways & Inhalation of hypertonic saline in rhDNase, mannitol \\
\hline \multirow[t]{4}{*}{ Lungs } & Bronchiectasis & Respiratory physiotherapy \\
\hline & Decline in lung function & Antibiotics, chronic anti-inflammatory therapy, bronchodilators, mucolytics \\
\hline & & Home oxygen therapy \\
\hline & & Lung transplantation \\
\hline \multicolumn{3}{|c|}{ Digestive system } \\
\hline Stomach & Gastroesophageal reflux disease & Proton pump inhibitors \\
\hline \multirow[t]{2}{*}{ Colon } & Distal intestinal obstruction syndrome & Hydration and laxatives \\
\hline & & Surgical procedure \\
\hline \multirow[t]{2}{*}{ Liver } & Liver failure & Ursodeoxycholic acid \\
\hline & Cirrhosis and complications & Treatment of cirrhosis \\
\hline \multirow[t]{3}{*}{ Pancreas } & Exocrine pancreatic insufficiency with malabsorption & $\begin{array}{l}\text { Pancreatic enzyme replacement therapy, fat soluble vitamins } \\
\text { supplementation }\end{array}$ \\
\hline & & High-calorie and high-protein diet \\
\hline & & Nasogastric tube or percutaneous gastrostomy \\
\hline \multicolumn{3}{|c|}{ Endocrine system } \\
\hline Pancreas & Diabetes & Insulin \\
\hline \multirow[t]{3}{*}{ Bones } & Osteopenia, osteoporosis with fractures & Caloric intake with the right ratio of fat, protein and carbohydrates \\
\hline & & Vitamin D, K, calcium \\
\hline & & Bisphosphonates \\
\hline \multicolumn{3}{|l|}{ Sweat glands } \\
\hline & $\begin{array}{l}\text { Hyponatremic hypochloremic dehydration with } \\
\text { possible cramps and arrhythmias }\end{array}$ & Fluid and salt replacement \\
\hline
\end{tabular}

Due to the all-encompassing nature of CF and its complications, management of the disease requires strong will and a lot of self-discipline and time, which can be a significant psychological burden. Daily management of CF may include inhalation and respiratory physiotherapy $2-3$ times a day, increased caloric intake and routine use of medications (11).

\section{Predictors of Workability}

As mentioned already workability is affected by many factors. The studies on workability of patients with $\mathrm{CF}$ are presented in Table 2.

\section{Education Level}

The results of the study published in 2011, including $207 \mathrm{CF}$ patients, presented that many patients with CF succeeded at study and work (6). CF patients had a higher level of education and were more likely to hold skilled jobs than the general population. However, two thirds thought that $\mathrm{CF}$ was an obstacle to their career. Over half of the patients reported being limited in their work by their disease. Three quarters of the patients who were not working reported that their disease was the main cause for their inactivity. The share of patients with CF who worked part-time was two to three times higher than in the general population. The authors of the study investigated factors that might be associated with work status. Work status was not associated with age, gender or daily time of treatment. Forced expiratory volume in 1 second $\left(\mathrm{FEV}_{1}\right)$ $(p=0.026)$ and educational level $(p=0.013)$ were the strongest predictive factors of disability. Having $\mathrm{FEV}_{1}$ value of less than $70 \%$ indicated an increase in the risk of disability, but this risk did not grow linearly as their clinical condition deteriorated. On the contrary, education level was a factor that was clearly associated with disability: the higher it was, the greater the chance of getting a job. Working part time helped to maintain employment despite declining health $(\mathrm{p}<0.01)$. Higher level of education also increased the odds of working full time (OR 1.74, 95\% CI 1.36-1.89), and the majority of adults with CF working full time reported a low percentage of problems with absenteeism and presenteeism (12).

Association between work status and level of education was proved by other authors as well $(5,11)$.

\section{Clinical Parameters of Disease Severity}

The severity of CF is evaluated by different clinical parameters: lung function defined by $\mathrm{FEV}_{1}$, number of courses of intravenous antibiotics, disease deterioration, body mass index, sputum microbiology, CF-related diabetes, lung transplantation and others $(5,6,11,13,14)$. Routine follow up of the course of disease is performed by measurement of $\mathrm{FEV}_{1}$.

The authors who studied the impact of clinical parameters of disease severity on workability of the patients with CF reported 


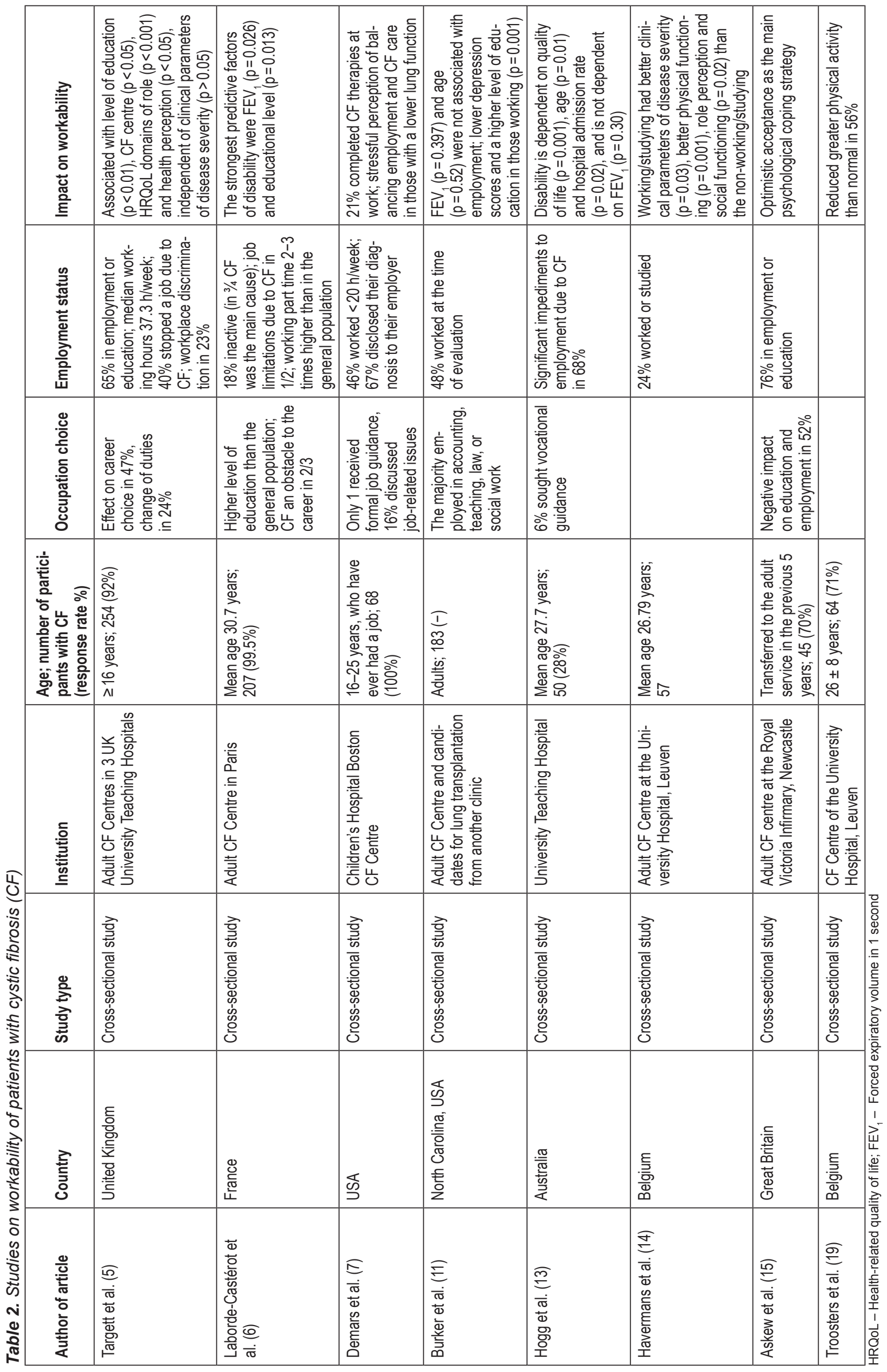


different results. Three research groups disproved the impact of clinical parameters of disease severity or $\mathrm{FEV}_{1}$ on work ability or work status $(5,11,13)$. Although one of them disproved the impact of $\mathrm{FEV}_{1}$, it reported that work disability was dependent on hospital admission rate (13). On the contrary, one research group marked $\mathrm{FEV}_{1}$ as the strongest predictive factor of work disability (6), while another one similarly reported that working/studying patients had better clinical parameters than those inactive (13). The authors also found out that respondents with a lower lung function were more likely to agree that 'balancing employment and CF care is stressful' (7).

The authors who found $\mathrm{FEV}_{1}$ value less than $70 \%$ as a risk factor of disability $(\mathrm{p}=0.05)$ also found at least one course of intravenous antibiotics per year as the same risk factor of disability (6).

\section{Health-Related Quality of Life}

The results of the largest study of work ability so far, in which 254 subjects were recruited (5), showed that $65 \%$ of subjects were in employment or education and they functioned well at work. If employed or self-employed, median hours worked was $37.3 \mathrm{~h} /$ week. Among respondents $40 \%$ reported stopping a job due to $\mathrm{CF}$, $47 \%$ felt that CF had affected their career choice, $24 \%$ changed duties because of CF, $10 \%$ had taken a pay cut, and $23 \%$ reported workplace discrimination due to $\mathrm{CF}$.

Employment status was independently associated with educational attainment $(p<0.001)$, CF centre $(p<0.05)$, and the health-related quality of life (HRQoL) domains of role and health perception $(p<0.01)$. The authors emphasized that health perception and role perception were far stronger predictors of employment status than lung function and exacerbations (5). This is likely related to disease mastery as described by other authors; regardless of your lung function, if you feel in control of your condition and have a positive outlook on your overall health, you are more likely to be able to obtain employment and function effectively in the workplace $(5,13)$. Authors concluded that specific guidance was needed for both adults with CF and potential employers, with appropriate targeted interventions aimed at improving health perceptions and coping strategies (5).

\section{Psychological Coping Strategy: Optimistic Acceptance}

The article from 2017 provides data on the characteristics of 45 young people with $\mathrm{CF}$ as they passed into adulthood that correlated to their transfer from the paediatric to the adult service (15). Researchers assessed coping strategies used in the transition process. The main psychological coping strategy the patients with CF used was optimistic acceptance. It was proved that those who believed in the importance of following medical advice and the benefits of treatment were likely to be more adherent to CF treatments. Although many had severe disease, they generally coped well with the transition, only $15.6 \%$ reported anxiety and $6.7 \%$ depression. Young adults were functioning well, with $76 \%$ in employment or education, $74-77 \%$ reported life satisfaction. Nevertheless, $52 \%$ felt that CF had a negative impact on education, employment and certain life situations. They required additional support in dealing with issues such as careers advice, employment rights, financial planning, and travel insurance.
A complicated interaction of numerous ecological variables (individual characteristics, personal contextual factors, mediating factors, and the environment) collectively influenced career development. The presence of CF alone did not guarantee negative effects on career development (16).

\section{DISCUSSION}

The patients with CF are seriously limited by impaired lung function, the associated need for respiratory physiotherapy and routine use of medications. Beside the exacerbations of lung disease their general health condition often requires hospital treatment (diabetes, intestinal obstruction, liver cirrhosis). Their physical capacity is reduced, they have to avoid risk factors and they must follow regular doctor's visits.

Chronic disease significantly limits their workability hence workability and work status are serious problems of these patients (1). It is well known that positive effects of work include improved financial prosperity, social participation, self-esteem, physical and mental wellbeing $(5,13)$. Accordingly, the patients with $\mathrm{CF}$ who are working assess their quality of life higher and have significantly lower depression scores $(11,13)$. The patients who are working report better physical functioning, role perception and social functioning compared to their non-working peers in spite of their medical status. This finding is worth taking into account when advice is given about reducing work or school load as working may protect patients from psychological problems (14). Some aspects of the quality of life reported by patients, especially physical functioning and pain, may be themselves predictors of survival in adults with CF $(6,17)$. Interactions between work, quality of life and possible survival call the healthcare workers to strive in helping their patients to succeed in their professional lives (6).

Workability of a patient with CF does not only relate to the severity of the disease but also to psycho-social factors such as illness perception and coping strategies (5). Therefore, it is of great importance that patients with CF interact with psychological and vocational rehabilitation professionals to promote optimal functioning and well-being (11). The manuals advise that $\mathrm{CF}$ should not prevent the patients from pursuing the career they wish. The patients should set their career goals that challenge them, they need to develop their talents and provide the activities that make them happy. But at the same time they should use common sense and know their own limits. The patients should be ready for changes in the career as their health changes $(17,18)$.

The physical capacity of adults with CF is often reduced. They are often able to perform mild physical activity, such as ground walking at a normal pace, but their ability to withstand greater physical activity is reduced (19). In the tertiary sector they are usually only slightly limited, thus employment in management and administration, data processing, commerce, banking, insurance, socio-cultural activities, and education is recommended (6). Unfortunately, only a few adolescents receive formal career guidance (7).

The health professions and occupations involving contact with children are often not recommended for CF patients, due to the higher risk of being exposed to respiratory pathogens. However, according to studies $10 \%$ of patients are employed in these sectors (6). 
Higher educational level improves the chances of attaining employment. Thus, a multidisciplinary team should encourage children and adolescents to achieve higher level of education (6). Besides, higher levels of education are likely to allow access to skilled jobs that are more amenable to the workplace adjustments. Once patient is integrated into the workplace, working hour reductions offer a way to maintain employment as the disease evolves and the constraints of treatment increase. Therefore, rather than choosing a specific trade, patients with CF should seek careers that allow some flexibility (6).

However, the evidence data of potential impact of CF on an individual's ability to work demonstrate that $\mathrm{CF}$ affected the work attendance of many but not all adults with CF. Many even reported that $\mathrm{CF}$ did not have a large impact on their work performance so further work is required to understand the full impact of $\mathrm{CF}$ on work performance (4).

\section{Guidelines Proposal on Career Counselling of Young Patients with CF and Suggestions for Professional Requalification}

When deciding what profession to choose and what occupation to perform it is a must to know workplace risk assessment and to define the risk factors that could have harmful impact on the patients with CF.

- Respiratory irritants (e.g. cigarette smoke, dust, fumes, paints, allergens, volatile chemicals, kitchen vapours, auto exhaust, moisture, high temperature) should be avoided. To work in places that are frequented by people who smoke is thus not appropriate (e.g. bars, nightclubs) (18).

- Work involving toddlers and school-age children (e.g. day care workers, elementary school teachers) and work in the health care increase the risk for viral and bacterial respiratory infections. Patients with CF may be carriers of dangerous pathogens, so work involving close contact with other patients with $\mathrm{CF}$ and immunocompromised patients is absolutely not recommended as it may cause a cross infection (18).

- Heavy manual labour (e.g. construction, agriculture) is usually physically too demanding. If a patient wishes to pursue such a trade anyway, it is better to look for a company that has the option of changing to a less physically demanding job in the future (e.g. moving to a desk job or supervisory position) (18)

- Workplaces with fast pace and rhythm of work (e.g. policeman, fireman), works that require intense concentration (e.g. stock broker, air traffic controller) and shift work, especially irregular and night shifts (e.g. 24-hours on duty occupations) are too burdensome for a CF patient and thus inappropriate (18).

- High altitude work (e.g. pilots, flight attendants, construction workers) is not appropriate as due to the severe lung disease oxygen blood level might drop too low. Exposing changing atmospheric pressures (e.g. flying airplanes, scuba diving) is inappropriate as well. CF patients might have blebs on their lungs, which can pop with changing air pressure, causing a dangerous air leak into the lining of the lung (18).

- Workplaces where CF patients come in contact with Pseudomonas aeruginosa are not appropriate, although complete avoidance is impossible. Exposure to water aerosol and to carriers of Pseudomonas aeruginosa present a particularly high risk of infection (1). Therefore, working in spa, jacuzzi and pool for hydrotherapy, work that involves bathing in standing water and work with aquariums is not appropriate. Pseudomonas aeruginosa is usually present in compost, where often also A. fumigatus can be found.

As career counselling to adolescents with $\mathrm{CF}$ is rare and poorly defined, we suggest the following guidelines:

- A young patient with CF should set career goals that will challenge them and develop their talents, but they should use common sense and know their limits. They should be ready for changes in the career as their health changes (18). The main coping strategy of the young patient with CF should be optimistic acceptance of themselves and their health condition (11).

- Disregarding the effect of the disease severity on work status, all the studies confirm that higher level of education improve the chances of attaining employment $(5,6)$. Besides, the patients with $\mathrm{CF}$ who were working evaluated their quality of life better than those who were not working. Hence, it is essential that healthcare workers encourage every patient to achieve the highest level of education possible and start gaining work experience. In essence, healthcare workers need to help their patients to succeed in their professional lives $(6,11)$.

- Similarly as the majority of adolescents with cystic fibrosis and their parents experience the barriers to treatment adherence, an opportunity for close cooperation between adolescents, their parents and healthcare professionals in overcoming adolescents adherence problems is indicated (20), multidisciplinary approach involving parents of young patients with cystic fibrosis, psychologists, social workers, and labour market specialists should be the most successful.

- Workplace adjustments, working hour reductions and/or working from home should be taken into account. The workplaces that allow flexible and reduced working hours, flexible use of vacation and sick leave benefits, additional paid or unpaid sick time and give the option of working from home are appropriate for the patient with CF. Careers in computer technology correspond with these conditions. Self-employment may bring many advantages as well $(6,18)$.

\section{CONCLUSIONS}

Patients with CF suffer limits to their workability because of their disease, its complications and reduced physical abilities for work performance.

While planning their professional career they have to be aware of the limitations caused by their chronical disease. Before finishing primary school education, the patients' psycho-physical abilities should be discussed and their professional goals revealed. Workplace risk assessment and risk factors at work are necessary to be defined so that the professions that could impact the health of patients with $\mathrm{CF}$ and also additionally reduce their workability are avoided. At lower ages the young patients with $\mathrm{CF}$ are still ready to direct and/or re-direct and also motivate to the more proper profession. Multidisciplinary approach involving parents and broader team of professionals would provide the most beneficial proposal.

The serious and empathic counselling in the team composed of a paediatrician, a psychologist and a specialist in occupational 
medicine is life-important. The optimal therapeutic treatment, the acceptance of young patients with CF of their own disease and the proper direction into professional career are the assurance that the adult patients with $\mathrm{CF}$ will find employment on the labour market. Economic independence will raise their satisfaction and self-esteem.

And finally, further work is required to understand the full impact of CF on work performance.

\section{Conflict of Interests}

None declared

\section{REFERENCES}

1. Praprotnik M, Krivec U. Manual for treatment of children and adolescents with cystic fibrosis. Ljubljana: Univerzitetni klinični center Ljubljana, Pediatrična klinika, Služba za pljučne bolezni; 2017. (In Slovenian.)

2. Krivec U. Respiratory diseases. In: Kržišnik C, editor. Pediatrics. Ljubljana: DZS; 2014. p. 363-5. (In Slovenian.)

3. Krivchenia K, Hayes D Jr, Tobias JD, Tumin D. Long-term work participation among cystic fibrosis patients undergoing lung transplantation. J Cyst Fibros. 2016;15(6):846-9.

4. Wood J, Jenkins S, Mulrennan S, Hill K. The impact of cystic fibrosis on work attendance and performance in adults living in rural and remote Western Australia. J Cyst Fibros. 2017;16(2):e1-e2.

5. Targett K, Bourke S, Nash E, Murphy E, Ayres J, Devereux G. Employment in adults with cystic fibrosis. Occup Med. 2014;64:87-94.

6. Laborde-Castérot H, Donnay C, Chapron J, Burgel P, Kanaan R, Honore I, et al. Employment and work disability in adults with cystic fibrosis. J Cyst Fibros. 2012;11(2):137-43.

7. Demars N, Uluer A, Sawicki GS. Employment experiences among adolescents and young adults with cystic fibrosis. Disabil Rehabil. 2011;33(11):992-6.

8. Praprotnik M, Bratanič N, Brecelj J, Fležar M, Salobir B, Kobe H, et al. Up-to-date management of liver disease and complications in cystic fibrosis and transition of adolescents from pediatric to adult care. Zdrav Vestn. 2015;84:222-31. (In Slovenian.)
9. Saldana PS, Pomeranz JL. Cystic fibrosis and the workplace: a review of the literature. Work. 2012;42(2):185-93.

10. Wright E. Sickness absence. In: Agius, Raymond M. Practical occupational medicine. 2nd ed. London: Hodder Arnold; 2006. p. 186-218.

11. Burker EJ, Sedway J, Carone S. Psychological and educational factors better predictors of work status than FEV1 in adults with cystic fibrosis. Pediatr Pulmonol. 2004;38(5):413-8.

12. Lian R, Cavalheri V, Wood J, Jenkins S, Straker LM, Hill K. Higher levels of education are associated with full-time work in adults with cystic fibrosis. Respir Care. 2019. Sep;64(9):1116-22.

13. Hogg M, Braithwaite M, Bailey M, Kotsimbos T, Wilson JW. Work disability in adults with cystic fibrosis and its relationship to quality of life. J Cyst Fibros. 2007;6(3):223-7.

14. Havermans T, Colpaert K, Vanharen L, Dupont LJ. Health related quality of life in cystic fibrosis: To work or not to work? J Cyst Fibros. 2009;8(3):218-23.

15. Askew K, Bamford A, Hudson B, Moratelli J, Miller R, Anderson C, et al. Current characteristics, challenges and coping strategies of young people with cystic fibrosis as they transition to adulthood. Clin Med. 2017;17(2):121-5.

16. Saldana PS, Pomeranz JL, Young ME. More than a job: Career development of individuals with cystic fibrosis. Work. 2018;59(3):425-37.

17. Abbott J, Hart A, Morton AM, Dey P, Conway SP, Webb AK. Can healthrelated quality of life predict survival in adults with cystic fibrosis? Am J Respir Crit Care Med. 2009;179(1):54-8.

18. Ferrin M, Cianci, K, Finnerty M, McDonald G, Smith T, Thrasher S. Cystic fibrosis in the workplace [Internet]. Betlehem, PA: Digestive Care; 2003 [cited 2017 Jun 11]. Available from: https://www.wvdhhr. org/cshcn/files/CFInTheWorkplace.pdf.

19. Troosters T, Langer D, Vrijsen B, Segers J, Wouters K, Janssens W, et al. Skeletal muscle weakness, exercise tolerance and physical activity in adults with cystic fibrosis. Eur Respir J. 2009;33(1):99-106.

20. Bregnballe V, Schiøtz PO, Boisen KA, Pressler T, Thastum M. Barriers to adherence in adolescents and young adults with cystic fibrosis: a questionnaire study in young patients and their parents. Patient Prefer Adherence. 2011;5:507-15.

Received November 27, 2018 Accepted in revised form July 22, 2019 